\title{
Lockjaw from a metastatic uterine leiomyosarcoma- case report and review of the literature
}

\author{
Isabel Hope ${ }^{1}$, Karen Morton ${ }^{2}$, Carrie Newlands ${ }^{2}$, Simon Butler-Manuel ${ }^{2}$ and Thumuluru Kavitha Madhuri ${ }^{2,3^{*}}$ (D)
}

\begin{abstract}
Background: Leiomyosarcoma (LMS) is a malignant tumour formed of cells with distinct smooth muscle features. Leiomyosarcomas rarely metastasise to the oral cavity and this literature review details all reported cases of metastasis to the mandible found in the literature. This offers a unique perspective by specifying mandible as the site of metastasis of leiomyosarcoma.
\end{abstract}

Case presentation: A 53-year-old female presented to her General Practitioner (GP) with heavy menstrual bleeding and was diagnosed with multiple fibroids. Folowing a hysterectomy and removal of both tubes and ovaries for these symptomatic uterine fibroids, an incidental diagnosis of low grade leiomyosarcoma was made. A CT scan found no evidence of residual or metastatic disease and no further treatment was deemed necessary. 6 months later she presented to A \& E with a numb lower lip but it took another 6 months for the diagnosis of metastatic LMS to the mandible to be made.

Discussion: Leiomyosarcomas are aggressive tumours which are liable to metastasise and therefore have a poor prognosis. An extensive literature review was undertaken to explore the frequency of metastasis in the maxillofacial region.

Conclusions: Although metastasis to the oral region is very rare as suggested from the literature review, when patients present with unusual symptoms after a diagnosis of LMS, physicians should be aware of the possibility of LMS metastases.

Keywords: Leiomyosarcoma, Metastases, Lockjaw

\section{Background}

Leiomyosarcomas (LMS) are smooth muscle tumours arising from the embryonic mesenchyme cell lines. Uterine LMS are aggressive tumours often associated with a poor prognosis however a rare entity accounting for $1 \%$ of cases with a uterine malignancy. Treatment is surgical in the early stage when the disease is confined to the uterus. Recurrent disease is diagnosed by the development of new symptoms such as the index case. Metastases to the oral cavity are rare and we report an interesting case of uterine LMS with metastases to the

\footnotetext{
* Correspondence: docmadhuri231@doctors.org.uk

${ }^{2}$ Royal Surrey County Hospital NHS Foundation Trust, Guildford, UK

${ }^{3}$ Department of Clinical \& Experimental Medicine, Faculty of Health and

Medical Sciences, University of Surrey, Guildford, UK

Full list of author information is available at the end of the article
}

mandible and review the literature to assess frequency of mandibular metastases.

\section{Case presentation}

A 53 year old female presented to her General Practitioner with heavy menstrual bleeding and was referred to a gynaecologist at her local hospital. Her previous medical history included one normal vaginal delivery aged 28, a Mirena IUS in situ, and, a normal cervical screening history. Drugs prescribed included ranitidine and citalopram. Family history included an identified BRCA mutation carried by her mother and aunt. She had not been genetically tested herself but underwent regular 6 monthly checks from ages 41 to 50 .

Multiple fibroids were identified on a trans-vaginal ultrasound of the pelvis. In view of her ongoing symptoms, the 
patient was offered a hysterectomy with a bilateral salpingo-oopherectomy.

The histology of the uterine specimen demonstrated one fibroid measuring $70 \mathrm{~mm}$ diameter and showing an abnormal focal area and central cystic necrosis consistent with a low grade leiomyosarcoma surrounded by normal tissue with no evidence of vascular infiltration. The leiomyosarcoma border was $10 \mathrm{~mm}$ clear of the serosal surface. A CT scan of the chest, abdomen and pelvis found no evidence of residual or metastatic disease and her case was discussed at a Gynaecologic Oncology multi disciplinary meeting (MDT). It was agreed that the likelihood of further metastasis was remote and she was discharged from follow-up.

Six months later, the patient presented to the accident and emergency department with a complaint of numbness in her lower left lip. A full neurological examination was normal so the patient was assured it would likely resolve. However, following a consultation with her dentist, she was referred to the maxillofacial department. The patient was known to grind her teeth due to anxiety. Altered sensation over left chin was reported, followed by numbness in her left lower lip. On examination, she was found to have decreased sensitivity to soft touch in the left mental nerve distribution area and an electric shock like sensation through her lip when pressure was applied to her mental foramen. Dental pulp testing with ethyl chloride was used on her lower left second premolar but no response was recorded and on $\mathrm{X}$-ray, the apex was found to be directly next to the mental foramen and an apical radiolucency was associated with this tooth. She was treated with a course of amoxicillin on the diagnosis of an apical infection affecting the mental nerve. Despite the antibiotic treatment, the numbness continued and the patient went on to develop dysesthesia of the left 4th and 5th fingers. She also experienced an episode of severe left-sided facial pain associated with difficulty in opening her jaw; the left side of her chin became swollen and rubbery to touch. Her left lower second molar was treated with a root canal filling, which also failed to improve her symptoms. Further neurological examination confirmed trigeminal motor function was unaffected and Tinel's sign was negative in the left elbow; peripheral nerve and Electromyography (EMG) studies were also found to be normal.

Magnetic resonance imagery of the brain and mandible along the course of the mandibular branch of the trigeminal nerve showed no evidence of metastasis. CT of the skull base, mandible and neck showed no bony abnormality and did not identify any prominent lymphadenopathy. Other investigations were undertaken, including chest X-ray, full blood count, ESR 5, clotting screen, B12 levels, plasma electrolytes, calcium, C reactive protein, angiotensin converting enzyme levels, liver function tests, thyroid function and blood sugar levels which were all normal. Tumour markers were tested and normal as well as Wassermann reaction, antinuclear factor, anticardiolipin antibodies, ANCA (antineutrophil cytoplasmic antibodies) screen and borrelia titres were negative, making any infective or autoimmune causes less likely. The patient declined to have a lumbar puncture (LP), instead wishing to try a course of acupuncture first. After completing her sessions of acupuncture over 4 weeks, she felt that the sensory disturbance in her left hand and left chin had improved by about $40 \%$. She therefore decided to carry on with another four sessions of acupuncture before considering a LP. Having finished the acupuncture, the patient found her left hand sensory disturbance to be almost completely resolved and her left chin was continuing to improve. She was prescribed antibiotics by her dentist to treat an abscess of the lower left wisdom tooth however this did not resolve the problem and led to a swelling in her left cheek. The left lower third molar was removed, and while extracting the tooth, a biopsy of abnormal 'moth eaten' looking soft tissue was also taken.

The histopathology report of the biopsy revealed an undifferentiated sarcomatous malignant tumour. Immunohistochemistry staining was used to compare this specimen to the uterine LMS from the hysterectomy previously and was consistent with recurrent disease. A second $\mathrm{CT}$ of the neck, abdomen and pelvis performed after an interval of 6 months revealed an extensive mass lesion affecting the left jaw and soft tissue mass on both sides (Fig. 1). A dental panoramic radiograph also showed a lobulated tumour within the angle of the mandible (Fig. 2). The final diagnosis of metastatic uterine LMS to the left mandible and masseter was made, over 6 months after the patient had initially presented with jaw paresthesia.

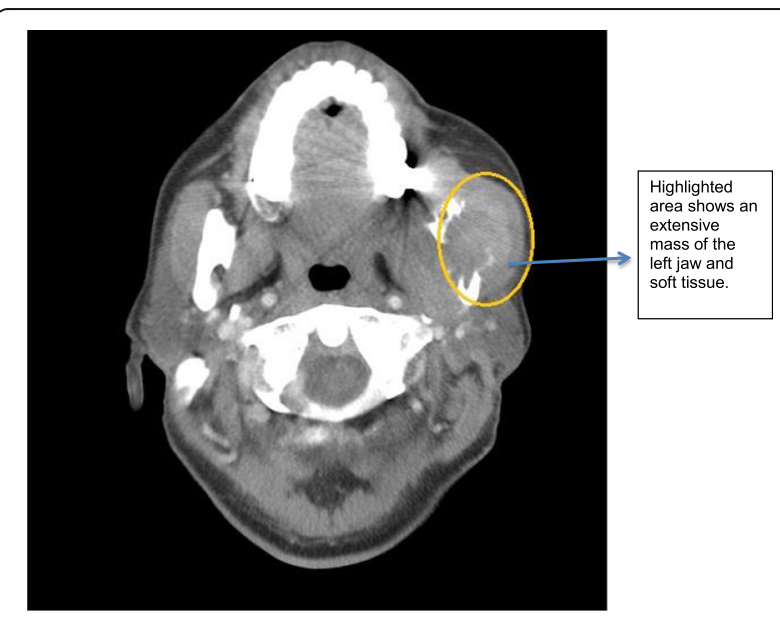

Fig. 1 showing a contrast enhanced axial $\subset T$ of the neck. Highlighted area shows an extensive mass of the left jaw and soft tissue 


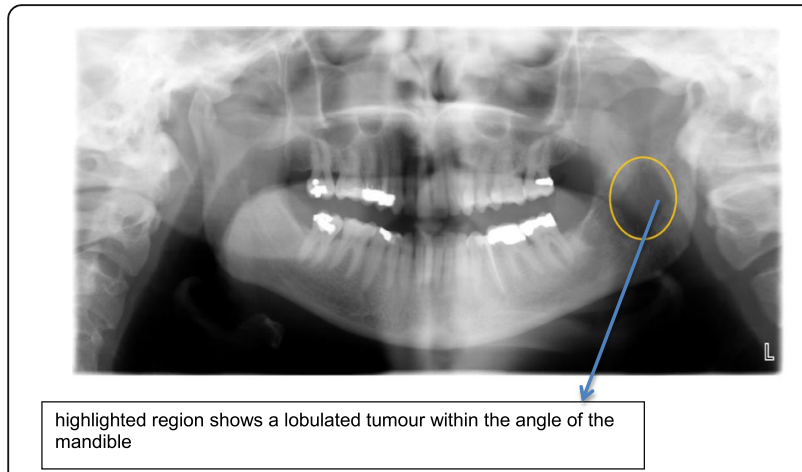

Fig. 2 Orthopantogram (OPG), highlighted region shows a lobulated tumour within the angle of the mandible

Primary treatment was resection of the masseter, medial pterygoid and angle of the mandible. A positron emission tomography (PET) scan was suggestive of small metabolically active area in pelvis, possibly further nodal spread, but it was not macroscopically visible on CT so no further excision was recommended.

Radiotherapy to the left mandibular lesion followed, with clinical follow-up. Further metastases subsequently developed with two lesions in the lungs, and one in the left pelvic side-wall. Diagnosis was made after a PET scan and the pelvic mass was treated with resection and radiotherapy. A pathological fracture to the humerus, secondary to the bony LMS metastasis at the site, lead to surgical correction and further radiotherapy. She later developed a metastatic lesion within the duodenum and underwent a pancreatic duodenectomy with resection of metastasis. An osteolytic mass was then identified in the right 4th rib and local palliation radiotherapy was administered. After further disease progression, 6 cycles of chemotherapy and palliative radiotherapy to the right iliac area, she died of progressive disease, 4 years following the original diagnosis of uterine LMS.

\section{Literature review}

A review of the literature was undertaken to assess frequency of mandibular metastases from uterine LMS. Databases including MEDLINE, EMBASE and google scholar were searched, the search being limited to the English language but with no time limit. Searching of the grey literature was also undertaken. Articles containing case reports of LMS metastasising to the 'oral cavity' were then further analysed to find cases specifically involving the mandible as a site of metastasis. From this thorough search, LMS metastasizing to the mandible was only reported in seven other cases, three from the uterus [1-3] as in this case, three from the lower limb $[4,5]$ and one from the abdomen (pancreas, abdominal aorta and vena cava) [6] (Table 1).
The index case is only the 4th reported case of uterine LMS metastasizing to the mandible found by this extensive search of the literature (Table 2) and highlights how rare the oral region is as a metastatic site, particularly as a first site of recurrent disease.

\section{Discussion}

Leiomyosarcoma (LMS) is a malignant tumour formed of cells with distinct smooth muscle features [7]. Uterine LMS originates from myometrium and represents $40 \%$ of uterine sarcomas [8] but with an incidence of only 0.4-0.64/100,000 women [8, 9]. 131,467 people were diagnosed with cancer in the UK in 2011. Of these 403 were women diagnosed with uterine sarcoma, 161 of these being uterine LMS.

Patients presenting with uterine LMS have a median age of 55 years and commonly present with vaginal bleeding (56\%), a palpable pelvic mass (54\%) and pelvic pain (22\%) [10]. However, most uterine leiomyosarcomas are detected during the histopathological analysis of a hysterectomy or myomectomy specimen [11] probably because these presenting symptoms are very similar with benign leiomyomas [12]. Uterine LMS most commonly spreads hematogenously to intra-abdominal viscera, lung, pleura para-aortic nodes and kidneys [10]. The prognosis in uterine LMS is poor in all stages of the disease and appears to be dependent on menopausal state. If the diagnosis is made in pre-menopausal women, the 5-year survival rate is $63.6 \%$ whereas in post-menopausal women the 5-year survival rate drops to $5.5 \%[10,13]$. This may be due to the hormonal environment, because preservation of the ovaries also seems to improve prognosis [11].

Pathologically, LMS structure is irregular and large with necrosis, haemorrhage, atypical nuclei and often with extra uterine extension [14]. Magnetic resonance imaging (MRI) will show a large composite mass that warps uterine architecture and contains necrosis and haemorrhage.

This case is unusual due to the location of the metastasis, as the oral cavity and oropharynx are rare sites of metastases from primary cancers of any organ. In fact, only $1-2 \%$ of oral malignant tumours are metastases from other primary sites [15]. However, the mandible is the most common site of these metastases to the oral cavity, with one paper [16] reporting that $55 \%$ of metastases to the oral cavity are to the mandible.

Clinicians need to remain suspicious of metastases in any site following treatment for a primary LMS. LMS are difficult to diagnose initially and there may be an inevitable delay in diagnosis due to investigation into infectious or erosive causes. However if a patient has a previous history of LMS, a metastasis should always be considered if they present with unusual symptoms, including in the jaw as in our patient. Consideration of 
Table 1 Results from literature search. Leiomyosarcomas metastasising to the mandible. Year journal article was published, author of journal article, primary site of leiomyosarcoma, metastatic sites, prognosis/follow up since metastatic diagnosis

\begin{tabular}{|c|c|c|c|c|c|}
\hline Year & Authors & Age/Sex & Primary Site & Metastatic Site & Survival \\
\hline 1986 & Tsounias et al. & $67 / F$ & Uterus & Mandible, lung, bones & 2 months died \\
\hline 1993 & Allen et al. & $61 / M$ & Thigh & Mandible, liver, spleen, lung, kidney & 3 years follow up \\
\hline 2000 & Dry SM et al. & $45 / F$ & Uterus & Maxilla, mandible & 11 months died \\
\hline 2011 & Azevedo et al. & $69 / M$ & $\begin{array}{l}\text { Pancreas, abdominal } \\
\text { aorta, vena cava }\end{array}$ & Liver, mandible & 1 year died \\
\hline 2011 & Jham BC et al. & $60 / M$ & Leg & Mandible & \\
\hline 2011 & Jham BC et al. & $69 / M$ & Leg & Mandible & \\
\hline 2013 & Fernandez-Barriales et al. & $49 / F$ & Uterus & $\begin{array}{l}\text { Mandible, masseter, maxilla, lung, } \\
\text { liver, vertebral body, lymph node }\end{array}$ & 18 months died \\
\hline 2015 & Hope et al. & $54 / F$ & Uterus & $\begin{array}{l}\text { Mandible, left masseter, humerus, } \\
\text { duodenum }\end{array}$ & 4 years died \\
\hline
\end{tabular}

metastatic LMS in a patient with a previous diagnosis is likely to allow for a swift diagnosis, and a possible improved prognosis. In this index case, it took over 6 months after the patient presented with sensory defects to be diagnosed with a metastasis to the jaw. Delay in the diagnosis and therefore treatment of metastatic LMS has the potential to allow the cancer to develop and increase the chance of further spread. A delay in diagnosis also prevents the onset of palliative care and leaves the patient symptomatic.

As can be seen by Table 2, this index case had the longest survival of all cases seen in the literature, at 4 years from presentation. Survival is influenced by many factors, the most influential in LMS being volume of tumour [6], presence of coagulative tumour cell necrosis, mitotic figures and cytologic atypia [17]. However, the aggressive treatment given in this index case could have played a part in her prolonged survival, with each new recurrence being treated with either surgery, chemotherapy, radiotherapy or a combination of the three. This contrasts with Tsounias et al.'s [1] treatment of solely surgery, and Fernandez-Barriales et al.'s [3] administration of chemotherapy and radiotherapy for the simultaneously diagnosed uterine primary and mandibular metastasis.

The referral of the index case to the supraregional centre for sarcomas may have improved outcome, due to experienced staff optimising the treatment given to

Table 2 All cases of uterine LMS metastasising to the mandible found in literature

\begin{tabular}{|c|c|c|c|c|c|c|c|c|c|c|c|}
\hline Year & Author & Age & $\begin{array}{l}\text { Metastatic } \\
\text { Sites }\end{array}$ & $\begin{array}{l}\text { Treatment } \\
\text { of Uterine } \\
\text { Primary }\end{array}$ & $\begin{array}{l}\text { Treatment } \\
\text { of } \\
\text { Metastases }\end{array}$ & $\begin{array}{l}\text { Disease free } \\
\text { interval }\end{array}$ & $\begin{array}{l}\text { Survival } \\
\text { from } \\
\text { diagnosis }\end{array}$ & $\begin{array}{l}\text { Survival } \\
\text { after } \\
\text { appearance } \\
\text { of } \\
\text { metastasis }\end{array}$ & $\begin{array}{l}\text { Cause of } \\
\text { death }\end{array}$ & $\begin{array}{l}\text { First symptoms of } \\
\text { metastasis }\end{array}$ & $\begin{array}{l}\text { Method of } \\
\text { diagnosis }\end{array}$ \\
\hline 1988 & $\begin{array}{l}\text { Tsounias } \\
\text { et al. }\end{array}$ & 67 & $\begin{array}{l}\text { Mandible, } \\
\text { lung, } \\
\text { bones }\end{array}$ & $\mathrm{S}$ & $\begin{array}{l}\text { S } \\
\text { (curettage) }\end{array}$ & $\begin{array}{l}12 \text { months } \\
\text { (uterine then } \\
\text { mandible) }\end{array}$ & $\begin{array}{l}1 \text { year } \\
2 \text { months }\end{array}$ & 2 months & $\begin{array}{l}\text { Metastatic } \\
\text { disease }\end{array}$ & $\begin{array}{l}\text { Pain in left } \\
\text { mandible }\end{array}$ & $\begin{array}{l}\text { X-ray then } \\
\text { surgery }\end{array}$ \\
\hline 2000 & $\begin{array}{l}\text { Dry SM } \\
\text { et al. }\end{array}$ & 45 & $\begin{array}{l}\text { Maxilla, } \\
\text { mandible }\end{array}$ & None & $S+R$ & $\begin{array}{l}1 \text { month } \\
\text { (uterine after } \\
\text { mandible) }\end{array}$ & 11 months & 11 months & $\begin{array}{l}\text { Metastatic } \\
\text { disease }\end{array}$ & $\begin{array}{l}\text { Loose teeth + } \\
\text { left nasal } \\
\text { congestion }\end{array}$ & Unknown \\
\hline 2013 & $\begin{array}{l}\text { Fernandez- } \\
\text { Barriales } \\
\text { et al. }\end{array}$ & 49 & $\begin{array}{l}\text { Mandible, } \\
\text { masseter, } \\
\text { maxilla, } \\
\text { lung, liver, } \\
\text { vertebral } \\
\text { body, } \\
\text { lymph } \\
\text { node }\end{array}$ & $C+R$ & $C+R$ & $\begin{array}{l}0 \text { months } \\
\text { (simultaneous } \\
\text { uterine }+ \\
\text { mandible) }\end{array}$ & $\begin{array}{l}1 \text { year } \\
6 \text { months }\end{array}$ & 18 months & $\begin{array}{l}\text { Metastatic } \\
\text { disease }\end{array}$ & $\begin{array}{l}\text { Hypoesthesia in } \\
\text { inferior alveolar } \\
\text { nerve territory } \\
\text { (NCS) }\end{array}$ & $\begin{array}{l}\text { Observation } \\
\text { of mass } \\
\text { then OPG }\end{array}$ \\
\hline 2015 & Hope et al. & 54 & $\begin{array}{l}\text { Mandible, } \\
\text { left } \\
\text { masseter, } \\
\text { humerus, } \\
\text { duodenum }\end{array}$ & S & $S+R+C$ & $\begin{array}{l}14 \text { months } \\
\text { (uterine then } \\
\text { mandible) }\end{array}$ & $\begin{array}{l}4 \text { years } \\
2 \text { months }\end{array}$ & 3 years & $\begin{array}{l}\text { Progressive } \\
\text { metastatic } \\
\text { disease }\end{array}$ & $\begin{array}{l}\text { Left lower lip } \\
\text { hypoesthesia } \\
\text { (NCS) }\end{array}$ & $\begin{array}{l}\text { Tooth } \\
\text { extraction, } \\
\text { biopsy of } \\
\text { tissue }\end{array}$ \\
\hline
\end{tabular}

Year of article publication, author, age of patient at diagnosis, metastatic sites of the uterine LMS, treatment of primary tumour and subsequent metastases, survival time from diagnosis, survival time after metastatic diagnosis, cause of death, first reported symptom of metastatic spread, method of metastatic diagnosis. 
this patient. At the time of referral, their diagnostic resources were superior to those in the local hospital: for example they could use PET to detect further metastases that were not apparent on CT.

\section{Conclusions}

This case demonstrates the possibility of LMS metastasising to the jaw and affecting nerves in this region, proving the aggressive nature of the tumour. If there is a recent history of leiomyosarcoma and a patient presents with nonspecific or unusual symptoms or with sensory disturbance in any system of the body, a secondary leiomyosarcoma should be considered in the differential diagnosis. Aggressive treatment in a specialist centre combined with the continued identification of new metastases may improve survival.

\section{Abbreviations}

A \& E: Accident \& Emergency; ANCA: Antineutrophil cytoplasmic antibodies; BRCA: Breast Cancer susceptibility gene; CT scan: Computed Tomography scan; EMG: Electromyography; GP: General Practitioner; IUS: Intra Uterine System; LMS: Leiomyosarcoma; LP: Lumbar puncture; MDT: Multidisciplinary Team meeting; MRI: Magnetic resonance imaging; PET: Positron emission tomography

\section{Acknowledgements}

Dr. Fuad Hussain- Consultant Radiologist for selection of images.

\section{Funding}

None

\section{Availability of data and materials}

Can be made available.

\section{Authors' contributions}

IH Project development, literature review, analysis, manuscript writing and editing, KM Project idea, manuscript review, CN project idea, manuscript editing and review, SBM literature review manuscript writing and editing, TKM Project lead- project development, student supervision, patient consent, manuscript writing and editing and corresponding author. All authors read and approved the final manuscript.

\section{Ethics approval and consent to participate}

Not needed as not a research study.

\section{Consent for publication}

Patient consent was obtained prior to preparing manuscript and uploaded as a supplementary material as part of the submission process.

\section{Competing interests}

All authors declare that they have no competing interest.

\section{Publisher's Note}

Springer Nature remains neutral with regard to jurisdictional claims in published maps and institutional affiliations.

\section{Author details}

${ }^{1}$ Faculty of Health \& Medical Sciences, University of Southampton, Southampton, UK. ${ }^{2}$ Royal Surrey County Hospital NHS Foundation Trust, Guildford, UK. ${ }^{3}$ Department of Clinical \& Experimental Medicine, Faculty of Health and Medical Sciences, University of Surrey, Guildford, UK.
Received: 25 May 2017 Accepted: 13 November 2017

Published online: 28 November 2017

\section{References}

1. Tsounias B. Metastatic uterine tumor to the oral cavity: case report and 20year review of the English literature. Ann Dent. 1988;47:26-7.

2. Dry SM, Jorgensen JL, Fletcher CDM. Leiomyosarcomas of the oral cavity: an usual topographic subset easily mistaken for nonmesenchymal tumours. Histopathology. 2000;36(3):210-20.

3. Fernández-Barriales M, Garcia-Montesinos B, Reija FG, Fernández MM, Bustillo RS. Metastatic leiomyosarcoma of the oral region from a uterine primary: a case report and review of the literature. J Oral Maxillofac Surg. 2013;71(9):1626-33.

4. Allen CM, Neville B, Damm DD, Maesh W. Leiomyosarcoma metastatic to the oral region - report of three cases. Oral Surg Oral Med Oral Pathol. 1993;76:752-6.

5. Jham BC, Salama AR, McClure SA, Ord RA. Metastatic tumours to the oral cavity: a clinical study of 18 cases. Head Neck Pathol. 2011;5(4):355-8.

6. Blythe J, Bari W. Uterine sarcoma: histology, classification, and prognosis: Global Library of Women's Medicine; 2008. https://www.glowm.com/section_view/ heading/Uterine\%2520Sarcoma\%3A\%2520Histology,\%2520Classification,\% 2520and\%2520Prognosis/item/242. Accessed 1 Dec 2015.

7. Evans HL, Shipley J. World Health Organisation classification of Tumours, pathology and genetics of Tumours of soft tissue and bone. Lyon: International Agency for Research on Cancer; 2002.

8. Benoit MF, Williams-Brown MY, Edwards CL. Gynecologic oncology handbook; an evidence based clinical guide. New York: Demos Medical Publishing; 2013.

9. Koivisto-Korander R, Martinsen Jl, Weiderpass E, Leminen A, Pukkala E. Incidence of uterine leiomyosarcoma and endometrial stromal sarcoma in Nordic countries: results from NORDCAN and NOCCA databases. Maturitas. 2012;72(1):56-60. http://www.sciencedirect.com/science/article/pii/ S0378512212000515. Accessed 4 Sept 15.

10. Di Saia PJ, Creasman WT. Clinical Gynaecologic oncology. 8th ed. Philadelphia: Saunders; 2012

11. Larson B, Silfverswärd C, Nilsson B, Pettersson F. Prognostic factors in uterine Leiomyosarcoma: a clinical and Histopathological study of 143 cases the Radiumhemmet series 1936-1981. Acta Oncol. 1990;29(2):185-91.

12. Harry VN, Narayansingh GV, Parkin DE. Uterine leiomyosarcomas: a review of the diagnostic and therapeutic pitfalls. Obstet Gynaecol. 2007;9:88-94

13. Gadducci A, Landoni F, Sartori E, Zola P, Maggino T, Lissoni A, Bazzurini L, Ariso R, Romagnolo C, Cristofani R. Uterine Leiomyosarcoma: analysis of treatment failures and survival. Gynecol Oncol. 1996;62:25-32.

14. Tirumani SH, Ojili V, Shanbhogue AKP, Fasih N, Ryan FG, Reinhold C. Current concepts in the imaging of uterine sarcoma. Abdom Imaging. 2013:38(2):397-411.

15. Meyer I, Shklar G. Malignant tumors metastatic to mouth and jaws. Oral Surg Oral Medi Oral Pathol. 1965;20:350-62.

16. Hirshberg A, Shnaiderman-Shapiro A, Kaplan I, Berger R. Metastatic tumours to the oral cavity- pathogenesis and analysis of 673 cases. Ora Oncol. 2008:44:743-52.

17. Kempson RL, Hendrickson MR. Smooth muscle, endometrial Stromal, and mixed Müllerian Tumours of the uterus. Modern Pathol. 2000;13(3):328-42. 